\title{
RUINA Y RECUPERACIÓN DE LA VIDA: LA HERMENÉUTICA EN EL JOVEN HEIDEGGER
}

\author{
Carlos Arturo Bedoya Rodas* \\ doi:10.11144/Javeriana.uph31-62.rrhh
}

\begin{abstract}
RESUMEN
El artículo se propone ofrecer un acercamiento a la concepción de filosofía que subyace al proyecto de una hermenéutica de la facticidad elaborado por Martin Heidegger entre 1919-1923. Esta aproximación se lleva a cabo a través del desarrollo que en la constitución de tal proyecto tiene el fenómeno de la ruina. La centralidad que este ocupa en el desarrollo temprano del pensamiento de Heidegger y, particularmente, en el curso del semestre de invierno de 1921/22, que lleva por título Interpretaciones fenomenológicas sobre Aristóteles. Introducción en la investigación fenomenológica, permite hacer comprensible el sentido que para el joven Heidegger constituye la tarea de la filosofía en esta temprana etapa como hermenéutica de la facticidad.
\end{abstract}

Palabras clave: hermenéutica; fenomenología; facticidad; joven Heidegger; ruina

\footnotetext{
* Pontificia Universidad Bolivariana, Medellín, Colombia.

RECIBIDO: 02.09.13 ACEPTADO: 06.11.13

DiSPONIBLE EN LÍNEA: 30.06 .14

El presente artículo de reflexión se encuentra enmarcado en la "Estrategia para la Sostenibilidad de los Grupos de Investigación 2013-2014" de la Universidad de Antioquia. Grupo inter-institucional "Filosofía y enseñanza de la filosofía".

Para citar este artículo: Bedoya RodAs, C.A. (2014). Ruina y recuperación de la vida: La hermenéutica en el joven Heidegger. Universitas Philosophica, 31(62), 95-112. ISSN 0120-5323; ISSN en línea 2346-2426; doi:10.11144/Javeriana.uph31-62.rrhh
} 


\title{
RUIN AND RETRIEVAL OF LIFE: HERMENEUTICS IN THE EARLY HEIDEGGER
}

\author{
Carlos Arturo Bedoya Rodas
}

\begin{abstract}
This paper provides an approach to the concept of philosophy underlying the project of a hermeneutics of facticity developed by Martin Heidegger throughout 19191923. This approach is accomplished via the development of the phenomenon of ruin in the creation of this project. The centrality this concept plays in Heidegger's early thought, most particularly during the winter term 1921-1922 in his Phenomenological Interpretations of Aristotle. Initiation into Phenomenological Research, allows us to understand the deep meaning of the task of philosophy as a hermeneutic of facticity at this early stage.
\end{abstract}

Key words: hermeneutics; phenomenology; facticity; young Heidegger; ruin 


\section{Introducción}

COMPRENDER CÓMO HA PODIDO LLEGAR A SER LA HERMENÉUTICA tan decisiva para la configuración del pensamiento contemporáneo, y cómo ha podido alcanzar un estatuto tan problemático $\mathrm{y}$, sobre todo, qué vigencia pueda seguir teniendo hoy ${ }^{1}$, supone la irrenunciable tarea de intentar esclarecer algunos de los motivos, fuentes y elementos que se encuentran en la base misma de los orígenes de la hermenéutica contemporánea. Efectivamente, esto demanda para el presente texto continuar ahondando en el pensamiento filosófico de Martin Heidegger, de modo particular, en el proyecto que este filósofo elaboró entre los años 1919 y 1923, el cual fue designado bajo el nombre de hermenéutica fenomenológica de la facticidad. En efecto, con el acercamiento a este proyecto, en lo que respecta a algunas de sus características, entre las cuales, como se verá, se destaca el desarrollo del concepto de ruina, se pretende posibilitar una comprensión del carácter específico de la hermenéutica heideggeriana, la cual, en ruptura con una concepción clásica y metodológica de la hermenéutica, ha determinado, como una de sus principales fuentes, a la hermenéutica contemporánea en tanto una filosofía universal de la comprensión (Cfr. Grondin, 2008: 18). De esta manera, las siguientes páginas intentan abordar algunos de los principales desarrollos que constituyen tal proyecto y de los que dan testimonios los textos de las lecciones tempranas, recientemente publicadas en el marco de la edición de las obras completas del filósofo alemán, Gesamtausgabe (GA). De modo particular, el artículo se centra en el curso del semestre de invierno de 1921/22 que lleva por título Interpretaciones fenomenológicas sobre Aristóteles. Introducción en la investigación fenomenológica ${ }^{2}$.

\footnotetext{
${ }^{1}$ Como desde hace un par de décadas lo ha señalado Vattimo, la hermenéutica llegaría a convertirse en una koiné universal (1991: 9, 55-71), y a tal punto este lenguaje universal ejercería tan gran influencia que llevaría a pensar que "son pensadores hermenéuticos no solo Heidegger, Gadamer, Ricoeur, Pareyson, sino también Habermas y Apel, Rorty y Charles Taylor, Jacques Derrida y Emmanuel Levinas" (Vattimo, 1995: 37). Ahora bien, recientemente se comienza a considerar que el origen de las concepciones más importantes de la hermenéutica filosófica contemporánea no solo pertenece al área continentalcentroeuropea sino también al ámbito del pensamiento analítico-anglosajón, con autores como Quine, Wilson, Davidson, Putnam, entre otros (Vigo, 2011: 172).

${ }^{2}$ (Heidegger, 1985). Este curso del que hasta ahora no cuenta con traducción en nuestro idioma, se articula dentro de las investigaciones del joven Heidegger como una introducción a un libro que pretendía publicar acerca de sus interpretaciones de la filosofía de Aristóteles. En este sentido, este curso que lleva el mismo título que el informe elaborado en octubre de
} 


\section{Heidegger y la hermenéutica}

Si Se aSegura Que con el Pensamiento de HeidegGer la hermenéutica ha asumido un estatuto propiamente filosófico (Cfr. Grondin, 2008: 45) ${ }^{3}$, cabe la pregunta acerca del lugar, en la obra de este pensador, desde el cual pueden hacerse evidentes los desarrollos que le permitirían a la hermenéutica los alcances que hoy resultan bien conocidos. De este modo, la hermenéutica del Dasein desarrollada en Ser y tiempo (1927) aparece como el lugar a partir del cual, y junto con los desarrollos posteriores de Gadamer, alcanzaría una dimensión del todo renovada que le permitiría convertirse en una filosofía universal de la interpretación (Cfr. Gadamer, 1998: 213-224). Sin embargo, aunque es evidente la centralidad que ocupan en esta obra los problemas referidos a la comprensión y a la interpretación, no deja de resultar paradójico, como el mismo Grondin lo anota, que la explicitación temática y sistemática de esta nueva concepción hermenéutica no ocupe más de media página en la obra de 1927, ya que, como es conocido, concedía mucho más espacio al planteamiento ontológico por el sentido del ser (Cfr. Grondin, 1999: 138).

La publicación de Ser y tiempo, sin duda, ha marcado el escenario del pensamiento contemporáneo, porque la pretensión de este proyecto ancla su mirada sobre el planteamiento de la pregunta por el sentido del ser. Sin embargo, como se declara desde su introducción, el planteamiento de esta "exige la previa y adecuada exposición de un ente (del Dasein) en lo que respecta a su ser" (Heidegger, 2003: 30) y, dado que este ente ya posee una comprensión del ser, debe hacer las veces de lo primeramente interrogado; de ahí que la primera exigencia que plantea el desarrollo de la pregunta por antonomasia de la filosofía sea la constitución de una analítica del Dasein,

1922 para optar a una cátedra en Marburgo, conocido bajo el nombre de Informe Natorp, y profundiza algunos de los temas elaborados en este (Kisiel, 1993: 232; Van Buren, 1994: 220).

${ }^{3}$ Grondin reconoce que definir la hermenéutica heideggeriana resulta un tema complejo. Quizá por ello pueden destacarse tres grandes concepciones posibles que se encuentran en el pensamiento de este filósofo alemán. Si bien, estas poseen distintos acentos, no se encuentran separadas, y se pueden distinguir así: una primera, la hermenéutica fenomenológica de la facticidad, ya perfilada hacia el año 1923; la segunda, la hermenéutica del Dasein en Ser y tiempo y, la tercera, más tardía, la hermenéutica de la historia de la metafísica. Empero, en esta última distinción ciertamente resulta mucho menos claro hablar de hermenéutica, con excepción de apenas algunos textos como en los Beiträge y en De camino al habla, donde Heidegger apenas menciona la hermenéutica (Cfr. Grondin, 2011: 141). 
de la que ciertamente no puede perderse de vista la provisionalidad de su carácter. Empero, esta marca que embarga al filosofar en Ser y tiempo tiene ya un primer desarrollo en los cursos que Martin Heidegger impartió como profesor no numerario en la Universidad de Friburgo entre 1919 y 1923; así lo consigna el filósofo en una nota a pie de página: "El autor se permite hacer notar que desde el semestre de 1919/1920 ha dado a conocer reiteradamente en sus cursos el análisis del mundo circundante y, en general, la «hermenéutica de la factibilidad» del Dasein" (Heidegger, 2003: 99)

En los primeros cursos que Heidegger imparte en Friburgo, y que en los últimos años han encontrado una resonancia más amplia ${ }^{5}$, tiene lugar el desarrollo de una concepción renovada de la filosofía de enorme importancia para la hermenéutica contemporánea. De ello dan testimonio quienes, como alumnos, asistieron a los mencionados cursos: Hans-Georg Gadamer, Herbert Marcuse, Karl Löwith, Leo Strauss, Hajiro Tanabe, Edith Stein,

\footnotetext{
${ }^{4}$ Para algunos especialistas, es en las lecciones tempranas de los años veinte donde el joven filósofo alemán desarrolla una explicitación más sistemática de un nuevo enfoque hermenéutico (Gutiérrez, 2002: 95; Gander, 2008: 142; Vigo, 2008: 231). De acuerdo con Gama, en la analítica del Dasein, la interpretación resulta ser solo un existenciario más dentro de los múltiples que definen el modo de ser del ser humano. En efecto, mientras que en Ser y Tiempo la interpretación se configura como una estructura ontológica al lado del comprender, el discurso o la Befindlichkeit, el acercamiento inicial a la facticidad que brindan las lecciones tempranas de los años 20 permite una mirada más comprehensiva de la complejidad del fenómeno de la interpretación, el cual se muestra en toda la dinamicidad del movimiento que ella representa (Cfr. Gama, 2011: 351).
}

${ }^{5}$ Actualmente, la literatura especializada generada a partir de la publicación de las lecciones del joven Heidegger gira alrededor de varias perspectivas exegéticas. Una de ellas considera que el valor de estas lecciones reside en ayuda a comprender la problemática filosófica de Ser y tiempo. Bajo esta línea de interpretación se pueden ubicar, en términos generales, las investigaciones de Kisiel, Van Buren, Fehér, Adrián, Xolocotzi, entre otros. Por lo contrario, la segunda tendencia considera que las diversas cuestiones tratadas en estos cursos no solo no se dejan reducir a la pregunta ontológica de la obra de 1927 sino que, incluso, poseen un interés filosófico propio. Bajo esta perspectiva se pueden ubicar, con algunos matices, las posiciones de Gadamer, Gander, Grondin, Rodríguez, De Lara, entre otros. De modo más reciente ha tomado fuerza otra interpretación a cargo de Steven Galt Crowell, quien considera que la relevancia filosófica del pensamiento de Heidegger en sus primeros cursos depende, en gran medida, de la estructura husserliana que la soporta - una fenomenología trascendental- sin desconocer, por supuesto, las diferencias con ésta. Para Crowell, la contribución de Heidegger no radica en una especie de "giro" hermenéutico, pragmático o posmoderno, sino que se mueve en el horizonte de la fenomenología trascendental (Cfr. Crowell, 2001: 6-12). 
Hans Jonas, Max Horkheimer, Wilhelm Szilasi, Ludwig Landgrebe, entre otros (Xolocotzi, 2009a: 25-29; 2009b: 493-502) ${ }^{6}$.

Entre 1919 y 1923, el carácter del filosofar para el joven Heidegger asume un ímpetu del todo renovado puesto que recupera el sentido por el que la filosofía no es solo la construcción de un movimiento teórico, que discurre de un modo paralelo a la vida, sino que es un movimiento de esta por llevarse a comprensión fundamental. Así, la filosofía asume el carácter de investigación radical a través del cual se despliega esa comprensión que ya tiene la vida. Lo anterior comienza a articularse para el joven profesor de Friburgo bajo el nombre de hermenéutica fenomenológica de la facticidad. Sin embargo, la realización de tal proyecto, esto es, el despliegue de esa comprensión que la vida posee, se torna en sí misma problemática desde su comienzo puesto que, si bien, la vida sabe de sí (Cfr. Heidegger, 1985: 88), este saber en mayor medida se le da de un modo desfigurador (Cfr. Heidegger, 2000: 52). Por tal razón, en la tarea de comprender en claridad la vida, se le presenta una dificultad estructural a la filosofía puesto que la vida, marcada por la facticidad, es brumosa (Cfr. Gadamer, 2002: 69).

Un lugar desde donde se comprende esta situación de la vida y, por lo tanto, de la filosofía, esto es, un eje articulador de todo el periodo friburgués, es precisamente el concepto de ruina, el cual será designado posteriormente como caída. Si bien, en Ser y tiempo el fenómeno de la caída (Verfallen) pone de manifiesto una modalidad existencial del estar-en-el-mundo, y junto con la existencialidad y la facticidad constituye, en el mismo nivel que los anteriores, uno de los caracteres ontológicos del ser del Dasein; ya desde comienzos de

\footnotetext{
${ }^{6}$ Un gran número de asistentes a las lecciones del joven Heidegger ha sido una figura destacada en la configuración de una parte importante del horizonte del pensamiento contemporáneo. En atención a esto, Xolocotzi sostiene que "algunos de esos planteamientos tuvieron su origen en las aulas donde Heidegger dictaba cátedra" (2009a: 25). Esta afirmación resulta evidente para el caso de Gadamer, quien afirma que: "Las clases de Heidegger hacían que las cosas parecieran tan inmediatamente próximas que ya no habría modo de distinguir si era él o el mismo Aristóteles quien estaba hablando. Era esta una de las más profundas verdades de la hermenéutica, que empezamos a experimentar entonces, y que más tarde intenté justificar y defender teóricamente" (1996: 253). Del mismo modo, Gadamer asegura en repetidas ocasiones la determinante influencia que su trabajo recibió a partir de las lecciones del joven Heidegger (1998: 379-382; 2002: 28-31, 41ss, 67ss, 277-291, 295-306). Para otros testimonios de quienes asistieron a los tempranos cursos de Friburgo puede verse: Wolin (2003), Xolocotzi (2007: 15-17) y Anders et al (2008).
} 
la década de los veinte, dentro de la explicitación del fenómeno de la vida fáctica que se lleva a cabo en la hermenéutica fenomenológica, este mismo fenómeno ocupa un lugar central constituyéndose en el sentido fundamental de la facticidad, esto es, en el modo primordial del movimiento de la vida. Efectivamente, y pese a toda su ambigüedad y oscuridad, la dilucidación de este fenómeno posibilita, por cuanto a partir de él se determina la necesidad del movimiento interpretativo (Cfr. Rodríguez, 1997: 190), una comprensión del carácter por el que la filosofía se articula para el joven Heidegger como hermenéutica fenomenológica de la facticidad.

\section{Vida fáctica, Mundo y Cuidado}

El trabajo filosófico de Martin Heidegger en sus primeros cursos en Friburgo, parte de una preocupación constante por la indagación del carácter de la filosofía. En efecto, bajo la pregunta por la definición de la filosofía (Cfr. Heidegger, 1985: 13) se constituye el inicio del camino del pensar del filósofo de Messkirch. En tal sentido, en el esfuerzo por apropiarse de ésta, encuentra la vida como un fenómeno fundamental, puesto que "en ella se posibilita el camino hacia la filosofía" (Heidegger, 2005: 11); es decir, la vida es su suelo originario, el lugar desde donde brota y al cual esta vuelve de un modo que le es completamente esencial. Por tal razón, emprende una interpretación categorial de este fenómeno en el semestre de invierno de $1921 / 22$.

La explicitación llevada a cabo en este curso revela fenomenológicamente el modo como la vida se relaciona permanentemente con el mundo, pues este es su horizonte de realización (Cfr. Heidegger, 1985: 93). En efecto, el vivir se encuentra siempre en una dirección hacia el mundo, que es designada bajo el nombre del cuidado (Sorge), el modo a través del cual la vida establece sus relaciones con el mundo. Así las cosas, la vida en esta explicitación no se presenta como un objeto fijo, determinable, sino como un fenómeno existencial en toda su realización; de ahí que la investigación filosófica, a diferencia de otro tipo de captaciones, deba aprehenderla de un modo fundamental, en otros términos, en su modo de ser; esto es, justamente, lo que Heidegger denomina facticidad (Faktizität).

Pese a la indeterminación que presenta este concepto a lo largo de esta etapa, por primera vez y sin justificación previa dentro del hilo del curso, la facticidad se articula de un modo ontológico como "el ser del vivir" 
(Das Sein des Lebens als seine »Faktizität«) (Heidegger, 1985: 114). Este carácter ontológico de la vida comienza a ser interpretado por Heidegger en términos de movilidad (Bewegtheit $)^{7}$. De esta manera, una explicitación de las estructuras de movimiento "en el cual y a través del cual la vida existe" (Heidegger, 1985: 117) hace posible al autor la articulación del cuidado y, con ello, la determinación categorial del ser de su mundo, esto es, la facticidad. Tal explicitación se despliega a través de categorías que son específicamente interpretativas, en las cuales, según el autor, "la vida viene hacia sí misma" (Heidegger, 1985: 88). En efecto, en este curso se lleva a cabo una oscura y ambigua dilucidación del movimiento que constituye el ser de la vida, a través de categorías que, dentro de una peculiar inseparabilidad, indican dinamismo desde su planteamiento: inclinación, distancia, bloqueo y, junto con ellas, lo que Heidegger denomina relucencia y preestrucción.

\section{La movilidad del cuidado}

BAJO LA INCLINACIÓN (NEIGUNG) SE DESIGNA una tendencia o dirección que la vida toma hacia su mundo, por lo que se ve abocada al trato con los objetos que le rodean. Esta dirección le imparte al vivir fáctico un peculiar peso. Éste, paradójicamente, no le viene dado desde afuera (Cfr. Heidegger, 1985: 119), sino que, por el contrario, es algo que está presente en y con él mismo. De esta manera, la inclinación le determina a la vida una dirección, precisamente, la que la conduce al mundo en el que se dispersa, de ahí que este se convierta en una fuente de toda posible auto-interpretación $\mathrm{y}$, por esto, la vida toma del mundo la representación que se hace de sí misma.

La segunda categoría de la vida fáctica es denominada distancia (Abstand) o también anulación de la distancia (Cfr. Heidegger, 1985: 103). Esta categoría, que se encuentra en relación con la inclinación, resulta cancelada por esta última. Efectivamente, el vivir se inclina hacia su mundo

\footnotetext{
${ }^{7}$ Con esto se señala una posible confrontación con el fenómeno del movimiento en Aristóteles (Cfr. Maggini, 1999: 101). Debido a algunas referencias aristotélicas que en este curso aparecen, se puede indicar que Heidegger elabora de una forma todavía no explícita una interpretación de la filosofía de Aristóteles. Si bien este curso lleva en su título una referencia explícita con respecto a Aristóteles en el marco de una elaboración de las categorías dinámicas de la vida fáctica, se debe reconocer que esta elaboración se efectúa en continuidad con la fenomenología de la experiencia religiosa, especialmente, de la experiencia agustiniana de la tentación (Cfr. Sommer, 2006: 1-3).
} 
y por la dispersión en que se encuentra no mantiene una distancia "ante" los objetos significativos del mundo, es así que no se apropia adecuadamente de la distancia frente a ellos. Con esta anulación de la distancia, al abandonarse totalmente a su mundo, la vida es objeto de una específica ocultación para sí misma.

Bajo el bloqueo (Abriegelung), como tercera categoría explicitada oscuramente por Heidegger, se concreta aún más la ocultación de que es objeto el vivir y que era ya insinuada en el tratamiento anterior. Este bloqueo expresa la situación de la vida, según la cual, en su estar inclinado que anula la distancia con el mundo del cuidado, se elude constantemente a sí misma como tal. En este sentido, en el Informe Natorp de 1922, asegura Heidegger que esa fuga del sí mismo se da a través del cuidado de un mundo socialmente constituido. En este informe, la fuga queda instaurada en la figura del uno (das Man) y se manifiesta en el lenguaje común (Cfr. Heidegger, 2002: 4041). Esta categoría indica una situación paradójica puesto que si bien la vida se bloquea a sí misma, o dicho de otro modo, se pone en la situación de "enmascaramiento" (Maskierung) (Cfr. Heidegger, 1985: 107), está en su constante mirar hacia nuevas significatividades del mundo, no se escapa de sí misma, pues siempre está buscándose.

Estas tres categorías del cuidado alcanzan un mayor nivel de aclaración una vez que configuran un movimiento unitario, el cual ocurre en un modo específico bajo dos direcciones que se co-implican y se sostienen mutuamente y que Heidegger denomina relucencia (Reluzenz) y preestrucción (Praestruktion). El movimiento por el cual la vida está siempre proyectándose hacia las cosas se designa como preestrucción. Sin embargo, en este encuentro con el mundo (Cfr. Heidegger, 1985: 119) el vivir refleja luz hacia sí mismo, constituyéndose con ello el movimiento de relucencia, por el cual, el vivir en el dirigirse hacia su mundo sabe de sí. Así, estas dos direcciones que determinan el dinamismo de la vida fáctica posibilitan una dilucidación de las categorías estructurales antes descritas.

La preestructuración y la relucencia que se interrelacionan mutuamente, como aspectos indisociables de la movilidad de la vida, determinan en cuanto movimiento unitario las categorías que constituyen el cuidado: el bloqueo entendido como huida de sí, afecta y estimula la inclinación. Ésta, a su vez, posibilita la anulación de la distancia en la que la vida no hace propio el espacio entre ella y lo que le sale al encuentro, por lo cual termina 
entregándose a múltiples posibilidades sin una apropiación en cada caso, y a partir de ello se le brindan nuevas ocasiones para el bloqueo. En cada una de estas categorías, la preestrucción y la relucencia se manifiestan como un movimiento en sí mismo, esto es, como en una especie de circularidad en la que toda preestrucción se dirige hacia su mundo y regresa hacia sí en el modo de la relucencia (Cfr. Martínez, 2005: 105).

\section{La ruina: el sentido fundamental de la vida fáctica}

LA ARTICULACIÓN ENTRE ESTAS CATEGORÍAS ES UNA EXPRESIÓN en la cual el sentido fundamental de la facticidad se anuncia, más aún, de acuerdo con Heidegger, la facticidad "es" este movimiento (1985: 127). En el curso de invierno de 1921/22 este sentido fundamental del ser de la vida se designa como Ruina (Ruinanz) y es definido bajo la indicación formal" como: "la movilidad de la vida fáctica que «realiza» y «es» vida fáctica en sí misma, como sí misma, para sí misma, por sí misma, y, en todo esto, contra sí misma" (Heidegger, 1985: 131) ${ }^{10}$. Efectivamente, el vivir fáctico en el modo de la relucencia, el saber de sí implícito, en el ocuparse del mundo, es decir, como preestrucción, no es propiamente transparente, sino desfigurador, de tal modo que se elude o rechaza hacia sí mismo.

Del mismo modo, el tratamiento de la ruina aparece en el Informe Natorp de octubre de 1922 en los mismos términos generales aquí planteados, pero bajo el nombre de caída (Verfallen). Según el informe, en el cuidado se manifiesta una inclinación hacia el mundo pero, en tal propensión, el cuidado queda absorbido por este y se deja arrastrar porél. Esta proclividad del cuidado manifiesta una tendencia fundamental de la vida "que la conduce hacia su propio declive (Abfallen) y por la que se produce un movimiento de caída (Verfallen) en el mundo que, a su vez, desemboca en el desmoronamiento

\footnotetext{
${ }^{8}$ Este es el término latino que en español traduce caída y que en lengua alemana corresponde a los términos Sturz, Unfall (Cfr. Georges, 1869: 2148).

${ }^{9}$ De acuerdo con Ramón Rodríguez, la indicación formal es el instrumento metódico que permite hacer justicia a la peculiaridad fenoménica de la facticidad, el cual, a su vez, sirve para dar una idea del estatuto de los conceptos filosóficos que explicitan la facticidad. En otros términos, la indicación formal es considerada como un metaconcepto que dice cómo son los conceptos de la hermenéutica de la facticidad (Cfr. Rodríguez, 2012: 157-176).

10 "Die Bewegtheit des faktischen Lebens, die das faktische Leben in ihm selbst als es selbst für sich selbst aus sich hinaus und in all dem gegen sich selbst »vollzieht«, d. h. »ist«".
} 
(Zerfall) de la vida misma" (Heidegger, 2002: 38). Sin embargo, Heidegger aspira a dejar en claro que esta ruina o caída no es simplemente un rasgo accidental de la vida, o un acontecimiento objetivo que le sucede; es, por el contrario, una modalidad intencional de la vida; $\mathrm{y}$, de un modo más particular, es "el destino más íntimo que afecta a la vida fáctica" (Heidegger, 2002: 39); por tanto, su apropiación pertenece constitutivamente a la facticidad.

Este sentido fundamental de la facticidad hace ya su aparición a través de algunas referencias desde el semestre de invierno de 1920/21 en el curso sobre la Introducción a la fenomenología de la religión. En el contexto de una explicación fenomenológica de la experiencia de la vida en el cristianismo primitivo (Cfr. Von Herrmann, 2007: 21-31), que se centra en algunas de las cartas paulinas, se hace manifiesta la tendencia cadente que constituye la experiencia fáctica. De este modo, la ruina aparece ya en los desarrollos del joven Heidegger en la distinción que, según éste, realiza San Pablo en la Primera Carta a los Tesalonicenses entre los llamados y los revocados. Frente a la inminencia de la parusía, la ruina caerá sobre estos últimos porque "no se tienen a sí mismos en la claridad del auténtico saber" (Heidegger, 2005a: 132), mientras los llamados, en tanto que hijos del día y de la luz deben permanecer vigilantes y sobrios (Cfr. Heidegger, 2005a: 133).

En el curso del semestre de verano de 1921 sobre San Agustín y el neoplatonismo, también es explicitada esta tendencia cadente o ruinante de la vida fáctica. Ciertamente, la interpretación del libro $\mathrm{X}$ de las Confesiones revela, de acuerdo con el joven profesor, la facticidad de la vida que se ve constituida por dos tendencias. En primer lugar, la que se dirige hacia la continencia (continentia), un movimiento contrario al desmoronamiento de la vida, lo que se corresponde con una preocupación auténtica consigo mismo. En el segundo, la que tiende hacia la dispersión (defluxius), con lo cual afirma Heidegger que "acecha la posibilidad más abismática de perderse-uno-a-sí-mismo" (Heidegger, 2001: 132) ${ }^{11}$.

\footnotetext{
${ }^{11}$ El tratamiento de la ruina que comienza a explicitarse en estos dos cursos y que parece, con algunos matices, relacionado con conceptos teológicos de la tradición cristiana (Cfr. Capelle, 2005: 115) responde a la pretensión fenomenológica de acceder a la vida fáctica en cuanto tal. En ese sentido, Heidegger alerta sobre la necesidad de evitar cualquier comprensión religiosa o ética de este concepto (Heidegger, 2001: 88).
} 
Como se ve, la configuración categorial de esta tendencia que se mantiene constante durante esta etapa de Friburgo, delata el movimiento de la vida que en el dirigirse hacia su mundo se pierde para ella misma, a partir de lo cual se obstaculiza cualquier posibilidad de autocomprensión originaria. Entre tanto, en términos fenomenológicos, este concepto permite señalar precisamente la radical copertenencia en la que la vida tiene al mundo como su asunto, dirección y horizonte (Cfr. Heidegger, 1985: 130). La ruina adquiere, pues, un lugar decisivo dentro de los desarrollos de este periodo puesto que muestra la facticidad de la vida y, con ello, posibilita comprender, como se podrá ver, las implicaciones de una hermenéutica fenomenológica en cuanto que ésta, como el mismo Heidegger lo declara, trata de "aclarar esa alienación de sí mismo de que está afectado el existir" (Heidegger, 2000: $33)$.

\section{La filosofía como un contramovimiento de la vida}

HASTA ESTE PUNTO SE HA DESTACADO LA RUINA como una determinación central en la explicitación de la vida pues expresa la movilidad fundamental de su ser. Sin embargo, para Heidegger, este movimiento ruinante, articulado en su sentido propio, es específicamente, pese a su declarada relevancia, tan solo un momento categorial de la facticidad (Cfr. Heidegger, 1985: 134). Con esto, la interpretación de la ruina que se ha esbozado a lo largo de estas páginas presenta un carácter ambiguo (Cfr. Rodríguez, 1997: 196; Redondo, 2001: 128), puesto que si bien esta es un modo de ocultación inevitable, no obstante, de acuerdo con el joven profesor de Friburgo, puede ser capaz de una superación que en cierta medida depende del vivir propio. De acuerdo con Heidegger, la ruina como un movimiento de la vida contra sí misma implica que esta «todavía» es otra cosa más y esta «otra cosa más» está desde luego presente en la ruina, incluso en el modo de su rechazo (Cfr. Heidegger, 1985: 132) $)^{12}$.

Siguiendo la línea de argumentación anteriormente señalada, el ocultamiento de la ruina de ningún modo puede ser absoluto, pues, dicho fenomenológicamente, el rechazo solo es posible sobre la base de algo que de alguna manera todavía se muestra. En este mismo sentido, el Informe

\footnotetext{
12 “[...]daß das Leben »noch« etwas anderes ist, welches andere in der Ruinanz zwar da ist, vorkommt, aber in der Weise des Abgedrängtwerdens"
} 
Natorp se declara en directa correspondencia con la situación aquí planteada, esto es, que la vida fáctica se anuncia para sí misma, aunque sea sometido a un inmediato rechazo:

La vida está fácticamente presente a sí misma, incluso cuando evita el encuentro consigo misma; es más, incluso cuando 'se distancia de sí', la vida se mantiene alerta frente a su absorción en las ocupaciones mundanas [...] la vida presta una atención más o menos expresa y no confesada hacia aquello ante lo que huye. (Heidegger, 2002: 43)

Por tal razón, si bien la ruina es un momento interpretativo del ser de la vida, este parece estar también constituido por otro momento, igualmente interpretativo, que se opone a esta tendencia ruinante, $y$ en el que es posible una aprehensión auténtica de la vida. En este sentido, según Heidegger, la vida misma manifiesta esencialmente una contramovilidad ('Gegen'bewegtheit) (Heidegger, 1985: 132). Así, esta se opone a la tendencia hacia la ruina o lo que posteriormente será denominado, la tendencia hacia la caída del cuidado. Pero este contramovimiento no significa una huida del mundo, es decir, no modifica la condición fáctica en la que en cada ocasión se encuentra la vida; lo que modifica, en cambio, es el tipo de actividad de la vida, el cual es la "consumación explícita y genuina de la tendencia a interpretar las actividades fundamentales de la vida en las que están en juego la vida misma y su ser" (Heidegger, 2002: 45). Efectivamente, este contramovimiento constituye lo que propiamente pertenece a la interpretación filosófica: "el filosofar es existencial contrarruinante" (Heidegger, 1985: 160) ${ }^{13}$.

Esta movilidad contrarruinante propia del filosofar se pone en ejecución a través de la posesión de un cuestionar apasionado, el cual es designado por Heidegger bajo el nombre de cuestionabilidad (Fraglichkeit) (Cfr. Heidegger, 1985: 152). Esta es un mantener la vida misma en un genuino interrogar, a través del cual la vida puede hacerse comprensible como una posibilidad que se despliega temporalmente (Cfr. Heidegger, 2002: 45). Dicho en los términos de las interpretaciones de los cursos de religión, la cuestionabilidad se hace presente a través del estar alerta en medio del estar siempre ocupado con el mundo, esto es, de un "tenerse-a-sí-mismo radical" (Heidegger, 2001: 136). Con todo, es esta cuestionabilidad existencial lo que para el joven Heidegger constituye el auténtico fundamento de la filosofía

13 "Das Philosophieren ist gegenruinant existenziell". 
(Cfr. Heidegger, 1985: 35). Precisamente este fundamento no es más que el giro radical por el que se obtiene el filosofar mismo, lo que, de acuerdo con el filósofo de Messkirch, puede ser dicho en los términos de lo que significa una conversión religiosa, es decir, de una "verdadera transformación radical" (Heidegger, 2005a: 45).

\section{La filosofía: Hermenéutica fenomenológica de la facticidad}

FRENTE A ESTE MOVIMIENTO RUINANTE por el que la vida se oculta a sí misma, la filosofía se presenta como la posibilidad que tiene la vida de saber de sí, y, a su vez, se configura en un contramovimiento de la misma vida. Sin embargo, para llevar a cabo la recuperación de la vida en esa ruina que la constituye, la filosofía debe acceder de un modo apropiado al ámbito originario del vivir, esto es, de un modo por el que no establezca ninguna distancia con éste. Heidegger cree encontrar esta posibilidad en una primera concepción de hermenéutica que se manifiesta a través de la idea de repetición (Wiederholung). Desde ésta, la filosofía como un modo fundamental de la vida misma, la «repite» auténticamente, esto es, retoma la vida de su caída [Abfall], y este retomar, en cuanto radical investigación, es la vida misma (Cfr. Heidegger, 1985: 80). Dicho de otro modo, la filosofía repite el movimiento mismo de la vida, y en esa repetición la retoma de la comprensión impropia que esta ofrece de sí misma.

Esta primera noción de hermenéutica que se manifiesta en la repetición implica dos momentos fundamentales que constituyen la filosofía según Heidegger: acceder adecuadamente a la vida y, al mismo tiempo, mantener este acceso libre de comprensiones impropias de ésta. El acceso adecuado al fenómeno de la vida implica, por su parte, mantenerse en la inmediatez en que este se da, de modo tal que no se establezca de entrada una actitud ante él. En este sentido, nuestro autor se distancia de la fenomenología husserliana por cuanto esta mantiene una actitud teórica que deforma el vivir de la vida en su inmediatez (Cfr. Heidegger, 2005b: 121-122).

Para Heidegger, el acceso a la cosa misma no se da de modo reflexivo sino, más bien, a través de una perspectiva en la que se identifica la vivencia con la vida misma, es decir, "la absoluta simpatía con la vida que es idéntica con el vivir mismo" (Heidegger, 2005b: 133). Su carácter absoluto radica en que esta actitud fundamental no se deriva de una realidad o posición que esté fuera de ella misma. Esta vivencia en la que se da originariamente la vida 
en la identidad consigo misma, es lo que desde su primer curso de 1919 se denomina "la intuición hermenéutica" (Heidegger, 2005b: 133).

Esta intuición, en la medida en que es un darse pre-reflexivo de la vida a sí misma, refiere al hecho de que esta tiene una comprensión de sí misma. Es en tal sentido que la tarea de la filosofía consiste en hacer explícita dicha comprensión, entendida no como sería la reflexión en la fenomenología, es decir, una modificación de la mirada (Cfr. Husserl, 1995: 172), sino como una prolongación de ese saber de sí que la vida posee. En este sentido, la filosofía es para Heidegger una forma fundamental de la vida misma, de tal modo que ella la repite auténticamente (Cfr. Heidegger, 1985: 80). Esta concepción de repetición que se muestra en la filosofía, que por su parte no es más que el despliegue de un comportamiento comprensivo que la vida misma posee (Cfr. Heidegger, 2002: 33), constituye la posibilidad por la cual la vida puede ser arrancada de su permanente estado de caída.

Así pues, el concepto de repetición presente en la filosofía, en cuanto esta despliega la comprensión que la vida tiene de sí misma, pone de manifiesto una primera noción de lo que significa la hermenéutica para el joven Heidegger. Asimismo, este concepto de repetición aunque no es del todo desarrollado en estas tempranas lecciones, manifiesta en cierta medida una concepción de la filosofía, según la cual esta se establece como la posibilidad de rescatar a la vida de su permanente ocultamiento, llevado a cabo por su tendencia ruinante. Tal posibilidad, como se ha intentado señalar de un modo escueto, no viene dada a través de una concepción en la que la filosofía pretende acceder a su objeto de un modo teorético, sino a través de un modo comprensivo, modo que le viene señalado a la filosofía desde el mismo objeto al que pretende acceder: la vida en su facticidad. Ésta, gracias a que posee una tendencia fundamental a comprenderse, esto es, a querer saber de sí misma, le señala a la filosofía en primera instancia lo que ella es, una expresión de la vida misma y, en segundo lugar, el modo como debe aprehenderla, un modo que Heidegger designa bajo el nombre de hermenéutica. 


\section{Referencias}

Anders, G. et al. (2008). Sobre Heidegger: cinco voces judias. (Trad. B. Ainbinder). Buenos Aires: Manantial.

Capelle, P. (2005). Heidegger. Reader of Augustine. Caputo, J.D. (Ed.). Augustine and Postmodernism: Confessions and Circumfession. Bloomington: Indiana University Press. (pp. 115-125).

Crowell, S. G. (2001). Husserl, Heidegger and the Space of Meaning. Illinois: Northwestern University Press.

Gadamer, H-G. (2002). Los caminos de Heidegger. (Trad. A. Ackermann Pilári). Barcelona: Herder.

Gadamer, H-G. (1998). Verdad y Método II. M. (Trad. Olasagasti). Salamanca: Sígueme.

Gadamer, H-G. (1996). Mis años de aprendizaje. (Trad. R. Fernández de Mauri Duque). Barcelona: Herder.

GAmA, L. E. (2011). Heidegger y los círculos de la interpretación. Rocha de la Torre, A. (Ed.). Heidegger hoy. Estudios y perspectivas. Buenos Aires: Grama Ediciones. (pp. 347-364).

GAnder, H-H. (2008). La fenomenología del vivir fáctico de Heidegger. Duque, F. (Ed.). Heidegger. Sendas que vienen Vol. I. Madrid: Círculo de Bellas Artes. (pp. 140-171).

Georges, Dr. (1869). Lateinisch-Deutsches Handwörterbuch. Leipzig: Hahn'sche Verlags- Buchhandlung.

Grondin, J. (2011). El paso de la hermenéutica de Heidegger a Gadamer. De Lara, F. (Ed.). Entre fenomenología y hermenéutica. Franco Volpi In Memoriam. México: Plaza y Valdés. (pp. 139-163).

Grondin, J. (2008). ¿Qué es la hermenéutica? (Trad. A. Martínez Riu). Barcelona: Herder.

Grondin, J. (1999). Introducción a la hermenéutica filosófica. (Trad. A. Ackermann Pilári). Barcelona: Herder.

Gutiérrez, C. B. (2002). Temas de filosofia hermenéutica. Conferencias y ensayos. Bogotá: Universidad Nacional de Colombia-Ediciones Uniandes. 
Heidegger, M. (2005a). Introducción a la fenomenología de la religión. (Trad. J. Uscatescu). Madrid: Siruela.

Heidegger, M. (2005b) La idea de la filosofía y el problema de la concepción del mundo. (Trad. J.A. Escudero). Barcelona: Herder.

Heidegger, M. (2003). Ser y tiempo. (Trad. J. E. Rivera). Madrid: Trotta.

HeidegGer, M. (2002). Interpretaciones fenomenológicas sobre Aristóteles (Indicación de la situación hermenéutica) [Informe Natorp]. (Trad. J. Adrián Escudero). Madrid: Trotta.

Heidegger, M. (2001). Estudios sobre mística medieval. (Trad. J. Muñoz). Madrid: Siruela.

Heidegger, M. (2000). Ontología. Hermenéutica de la facticidad. (Trad. J. Aspiunza). Madrid: Alianza Editorial.

Heidegger, M. (1985). Phänomenologische Interpretationen zu Aristoteles. Einführung in die Phänomenologische Forschung, G.A. 61. Frankfurt am Main: Klostermann.

Husserl, E. (1995). Ideas relativas a una fenomenología pura y una filosofía fenomenológica. (Trad. J. Gaos). México: Fondo de Cultura Económica.

Kisiel, T. (1993). The Genesis of Heidegger's Being and Time. Berkeley: University of California Press.

Maggini, G. (1999). Movement and the Facticity of Life: On Heidegger's Early Interpretation of Aristotle. Philosophical Inquiry International Quarterly. Vol. 21, No. 2. (pp. 93-108).

Martínez, P. (2005). La dinámica de la facticidad. Revista de filosofía. Vol. 30, No. 2. (pp. 89-118).

Redondo, P. (2001). Experiencia de la vida y fenomenología en las lecciones de Friburgo de Martin Heidegger (1919-1923). Salamanca: Ediciones Universidad de Salamanca.

Rodríguez, R. (2012). La indicación formal y su uso en Ser y tiempo. Rodríguez, R. \& Cazzanelli, S. (Eds.). Lenguaje y categorías en la hermenéutica filosófica. Madrid: Biblioteca Nueva. (pp. 157-176).

Rodríguez, R. (1997). La transformación hermenéutica de la fenomenología. Una interpretación de la obra temprana de Heidegger. Madrid: Tecnos. 
Sommer, C. (2006). L'Inquiétude de la vie facticielle. Le tournant aristotélicien de Heidegger (1921-1922). Les Études philosophiques. No. 1, 1-28.

Van Buren, J. (1994). The Young Heidegger. Rumor of the Hidden King. Bloomington: Indiana University Press.

VAtтimo, G. (1995). Más allá de la interpretación. (Trad. R. Rodríguez). Barcelona: Paidós.

Vattimo, G. (1991). Ética de la interpretación. (Trad. T. Oñate). Barcelona: Paidós.

Vigo, A. (2011). Caridad, sospecha y verdad. La idea de la racionalidad en la hermenéutica filosófica contemporánea. De Lara, F. (Ed.). Entre fenomenología y hermenéutica. Franco Volpi In Memoriam. México: Plaza y Valdés. (pp. 165-202).

Vigo, A. (2008). Arqueología y aleteiología y otros estudios heideggerianos. Buenos Aires: Biblos.

Von Herrmann, F-W. (2007). Faktische Lebenserfahrung und urchristliche Religiosität. Fischer, N. \& Von Herrmann, F-W. (Eds.). Heidegger und die christliche Tradition. Hamburg: Felix Meiner Verlag. (pp. 21-31).

Wolin, R. (2003). Los hijos de Heidegger. Hannah Arendt, Karl Löwith, Hans Jonas y Herbert Marcuse. (Trad. M. Condor). Madrid: Cátedra.

XоLосотzi, Á. (2007). Subjetividad radical y comprensión afectiva. El rompimiento de la representación en Rickert, Dilthey, Husserl y Heidegger. México: Plaza y Valdés.

Xolocotzi, Á. (2009a). Facetas Heideggerianas. México: Benemérita Universidad Autónoma de Puebla.

Xolocotzi, Á. (2009b). La «Escuela» friburguesa de Heidegger. En M. Cepeda \& R. Arango (eds.). Amistad y alteridad. Homenaje a Carlos B. Gutiérrez (493-502). Bogotá: Universidad de los Andes. 